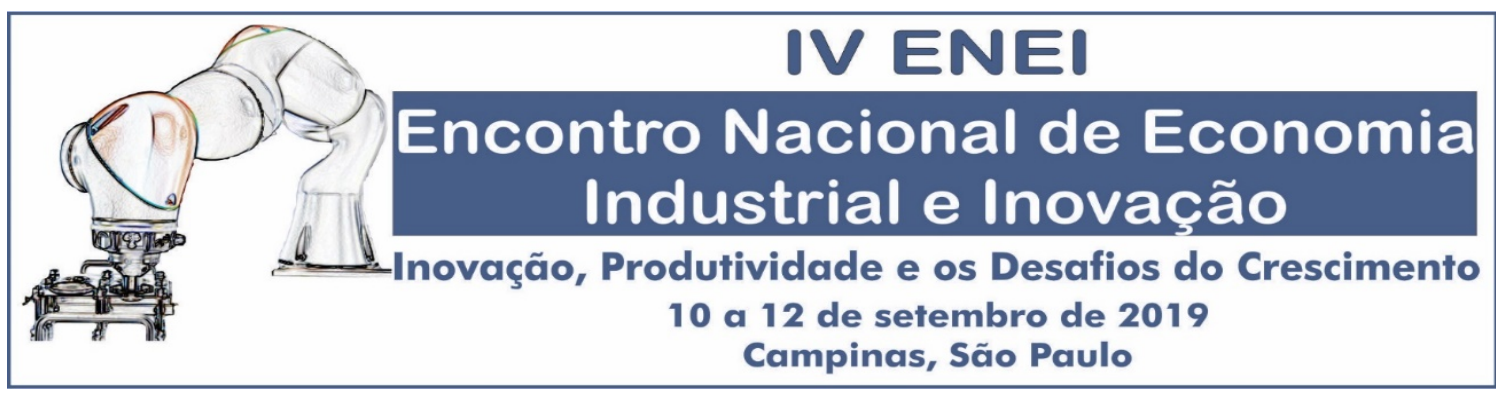

\title{
A Indústria 4.0: Uma análise comparativa entre as experiências da: Alemanha, EUA, China, Coréia do Sul e Japão.
}

\author{
Felipe Andrade Lucena* \\ José Eduardo Roselino ${ }^{\dagger}$
}

\section{Resumo}

O presente artigo se refere ao fenômeno da quarta revolução industrial e o papel das principais potências globais em relação a ele. Atualmente observa-se a retomada das políticas industriais pelos principais países centrais. Esse fenômeno está associado à nova onda de tecnologias da informação que impactam o sistema produtivo, sendo chamado pela literatura de quarta revolução industrial ou Indústria 4.0. A Indústria 4.0 despertou o desenvolvimento de políticas industriais por parte das economias a fim de atingir um espaço de destaque no cenário manufatureiro global. Destaca-se a corrida entre Alemanha, Estados Unidos, Coréia do Sul, Japão e China para captar as vantagens que a Indústria 4.0 oferece. Apesar de contarem com políticas industriais para a Indústria 4.0, esses países tem diferentes motivações para a mesma, destaque para a China que preparou uma série de medidas a fim de se tornar a principal potência manufatureira por torno do ano de 2050.

\section{Palavras-Chave: Indústria 4.0, Politica Industrial, China}

\section{Abstract}

This study is about the phenomenon of the 4th industrial revolution and the role of the main global players in it. Actually, there is retaken of industrial policies by the main global economies. That is associated to the new wave of information technology which impacts the economy. This phenomenon is also called by the literature as 4.0 Industry. The 4.0 industry brought industrial policies for the main global powers in order to achieve a supreme rule in manufacture market. This race is placed between Germany, the United States, South Korea, Japan and China to capture the advantages that Industry 4.0 offers. Although they have industrial policies for Industry 4.0, these countries have different motivations for the industry, especially China, which has prepared a series of measures to become the main manufacturing power around 2050.

Keywords: Industry 4.0, Industrial Policy, China

\footnotetext{
* Mestrando em Economia pela Universidade Federal de São Carlos. E-mail: felipelucena1@gmail.com

† Professor do Programa de Pós-Graduação em Economia da Universidade Federal de São Carlos. Email:jeroselino@ufscar.br
} 


\section{JEL Code: L5 Regulation and Industrial Policy}

\section{Introdução}

O decorrer da última década foi marcado por acontecimentos que transformaram o cenário geopolítico e econômico mundial. O panorama global foi marcado por modificações profundas que redesenharam o curso do processo político e econômico contemporâneo. Como exemplos desses acontecimentos têm-se os impactos da emergência da China como nova potência das esferas econômicas e geopolíticas, colocando em perigo a dominância dos países ocidentais, bem como o retorno de estratégias industrializantes ativas e protecionistas pelos países desenvolvidos.

Por outro lado, a recente guerra comercial entre EUA e China demonstra um esforço protecionista estadunidense que tenta conter a perda do seu setor manufatureiro para a China e visa proteger seu ecossistema industrial e seu sistema nacional de inovação, buscando recuperar a quantidade de empregos industriais da economia estadunidense após décadas de declínio, sobretudo nas vagas em empregos de menor valor agregado (as típicas ocupações de "chão de fábrica").

Por trás desse cenário existem hipóteses sobre os combustíveis que dão energia às mudanças globais em curso. Tanto do ponto de vista social, político ou econômico, existe um fato comum que une as esferas mencionadas: a presença e o uso crescente das tecnologias da informação (TIC) no dia-a-dia. As TIC possibilitam interações sociais (com o uso crescente de mídias sociais que conectam os cidadãos de diferentes países e os expõe a um conjunto de dados e informações jamais obtidas antes na história da humanidade), avanços no âmbito empresarial (intensificando interação entre produtor e cliente), e avanços no setor produtivo (graças ao barateamento da TIC foi possível a redução de custos através das rotinas produtivas, como a digitalização de processos). As TICs formam a base para a Indústria 4.0 fazendo parte dela e servindo como uma de suas tecnologias base.

A importância dessa adoção para o setor produtivo é relevante para os países em vários sentidos: pela capacidade de expansão das vantagens comparativas do país que a adota, pela busca em atingir elos mais elevados nas cadeias globais de valor, pela manutenção ou elevação na sua posição de destaque internacional e pela busca de captar atividades produtivas de maior valor agregado.

Segundo Majerowicz e Medeiros (2018), o progresso técnico tem sido essencial para as dimensões de poder dos países. Os autores sintetizam como a proximidade entre manufatura e o setor militar pode ser determinante para a dimensão de poder nacional no cenário global. Essa relação entre a tecnologia e a manufatura é de suma importância para as sociedades.

A corrida pelo progresso técnico mobiliza as capacidades dos governos nacionais de provirem e darem suporte ao mecanismo de inovação, criação e expansão de novas tecnologias (Chang, 2013). Manufatura e o progresso técnico possuem papel fundamental para defesa nacional. Majerowicz e Medeiros (2018), demonstram a iniciativa chinesa frente aos semicondutores (tecnologia chave para controle de mísseis balísticos, entre outras tecnologias acopladas à defesa). Allen (2019) analisa a política industrial chinesa e sua relação com estratégia de poder, para isso deve assegurar a produção interna de tecnologias chave (tal como os semicondutores) para a proteção nacional. 
As políticas industriais estão presentes ao longo da história das civilizações de forma a demonstrar a importância do progresso técnico ao longo do tempo. O progresso técnico é definido na literatura como saltos tecnológicos ou, revolução industrial. O termo revolução industrial consiste na adoção de tecnologias chave que revolucionam parte substantiva dos processos produtivos.

Partindo da problemática até aqui apresentada, pesquisadores buscaram sintetizar, caracterizar e analisar o atual cenário da manufatura global. Autores como Schwab (2018), Chen et al. (2014), defendem que está em curso uma nova revolução industrial, cronologicamente sendo a quarta revolução industrial, chamada de Indústria 4.0. a Industria 4.0 segundo eles estão relacionadas às TICs.

Para Daudt e Willcox (2016) o elemento fundamental da Indústria 4.0 é a fusão do mundo virtual e do mundo real, através da utilização de sistemas cyber-físicos (unidades de produção com representação virtual que permitem maiores níveis de automação). Concomitante, esse processo resultaria em maior flexibilidade da cadeia produtiva, com informação disponível em tempo real para fornecedores e clientes.

Segundo Majerowicz e Medeiros (2018), a importância da Indústria 4.0 para a ciência e tecnologia relaciona-se diretamente com o setor de defesa, sendo notável essa interação através das políticas de desenvolvimento de semicondutores por parte das principais potencias globais.

A importância da indústria dual (indústria que serve a fins bélicos e comerciais) é atualmente destacado por Allen (2019), com ênfase para política industrial chinesa voltada à tecnologia de Inteligência Artificial (IA) e semicondutores. Essa tecnologia é importante e estratégica porque é utilizada amplamente no controle de armas balísticas, como mísseis. Do ponto de vista da segurança nacional, é de interesse governamental manter essa tecnologia desenvolvida no próprio país a fim de controlar sua estrutura de valor internamente proferindo uma vantagem em termos militares.

Alicerçados na relevância que o desenvolvimento tecnológico manufatureiro tem para economia e para a soberania nacional, o objetivo desse artigo é fazer uma análise comparativa sobre as estratégias industriais dos principais players do setor high tech, com enfoque nas experiencias alemã, estadunidense, japonesa, sul coreana e enfoque maior para a experiência chinesa. Apesar da China não se posicionar atualmente entre os maiores produtores de tecnologia high tech, como Estados Unidos da América, Alemanha, Coréia do Sul e Japão, assume-se a hipótese de que esse país tem criado capacitações produtivas e tecnológicas a níveis da Indústria 4.0 de forma a alcançar lugar de destaque no cenário da indústria moderna.

O artigo se divide em 4 seções, na primeira seção é abordada a Indústria 4.0 para isso foi elaborado um referencial teórico sobre o tema. A seção dois define as tecnologias da Indústria 4.0, listando-as e explicando a sua atuação econômica. Seção três se refere as políticas industriais da Alemanha, EUA, Coréia do Sul, Japão, e China listando suas principais ações em direção a Indústria 4.0. Por fim, A quarta seção conclusiva traz o debate comparativo entre as políticas industriais listadas anteriormente, fazendo uma síntese com seus principais aspectos.

\section{A Indústria 4.0}

Está em curso uma nova onda de mudanças tecnológicas que afetam a manufatura global. Esse tema vem sendo o núcleo de debates de pesquisadores relacionados à indústria. $\mathrm{O}$ debate é rico e apresenta distintas visões acerca do tema. Os autores, 
entretanto, geralmente convergem em eleger as principais tecnologias desse processo, bem como em apontar as principais consequências das mesmas para a economia e a sociedade. Esta sessão tem como objetivo definir a arquitetura por trás da quarta revolução industrial também conhecida por Industria 4.0 nome esse dado através do plano alemão Industrie 4.0 em 2008 pioneiro em definir as principais tecnologias desse progresso tecnológico.

A literatura especializada buscou definir o que é a quarta revolução industrial. Xu et al (2018), define a quarta revolução industrial como um aprofundamento e continuação da terceira, seu direcionamento está nas tecnologias da informação e comunicação (ICT o termo em inglês). Jasperneite (2012), diz que a Indústria 4.0 é representada pelos sistemas cyber físicos (CPS), internet das coisas (IoT), e a computação em nuvem (cloud computing). Schwab (2018), diz que a Indústria 4.0 é uma maneira de descrever todo o conjunto de transformações em curso ao qual emanam dos sistemas de tecnologia da informação que nos rodeiam.

Por outro lado, há, por alguns, ceticismo em relação à caracterização das transformações em curso como uma quarta revolução industrial. A contestação se baseia na proposição de que esse processo, definido como Indústria 4.0, significa uma continuação ou desdobramento da terceira revolução industrial. Conforme HirschKreinsen (2016) destaca, essa questão só pode ser justificada pela percepção de que a Indústria 4.0 dificilmente seja distinguida dos conceitos de sua predecessora, tal como a centralidade das tecnologias produtivas baseadas em TI.

A partir da definição do que é Indústria 4.0, geram-se as discussões subsequentes sobre a sua importância e seus aspectos fundamentais. Schwab (2018), destaca a importância de se enxergar a tecnologia como algo que vai além de uma força inevitável, de forma a encontrar e fornecer às pessoas a maior capacidade de impactar a sociedade $\mathrm{e}$ os sistemas que os rodeiam. Por outro, lado Arbix et al. (2017), afirmam que a Indústria 4.0 pretende ser a expressão do novo capítulo na trajetória das transformações industriais que prenunciam as novas sínteses entre homens, máquinas e as tecnologias de inteligência de softwares e algoritmos.

Segundo Wang et al. (2015), o princípio básico da Indústria 4.0 está na internet das coisas (IoT) e na manufatura inteligente, possibilitando que componentes e máquinas coletem e compartilhem dados em tempo real, levando à mudança de uma fábrica centralizada para uma de inteligência descentralizada. Isso permite com que máquinas e plantas industriais se adaptem às mudanças, alterando ordens e condições de operação por meio de um processo auto adaptativo e de reconfiguração (Wang et al., 2015).

Sobre os impactos estruturais , o relatório MGI (2012) afirma que a Indústria 4.0 traz consigo maior orientação para demanda dos países em desenvolvimento, graças à aceleração do ritmo de crescimento desses, proliferação de produtos para atender à fragmentada demanda dos consumidores, aumento da importância dos serviços de alto valor agregado, maior pressão sobre recursos naturais, cadeias produtivas e processos mais sustentáveis.

Dessa forma, as fronteiras entre fabricação e montagem tendem a desaparecer graças aos processos de automação, além de que os processos de reaproveitamento de rejeitos industriais que apontam para uma nova dimensão da reciclagem, prolongando o ciclo de vida dos produtos em um sentido mais amplo do que as preocupações ecológicas ou ambientais (Schwab, 2018). 
Tendo em vista os impactos, discussões e caracterizações por trás da Indústria 4.0, pode-se concluir que ela é baseada nas tecnologias de informação (TI), mais especificamente na computação móvel, nos armazenamentos em nuvem, no Big Data, robótica, nanotecnologia, design, técnicas de impressão em terceira dimensão (impressoras 3D), fabricação aditiva, realidade virtual aumentada. Além disso, a importância do armazenamentos em nuvem e a computação móvel se dá para a provisão de serviços que podem ser acessados globalmente pela Internet (Roblek, Meško e Krapež, 2016).

\section{Tecnologias da Indústria 4.0}

As tecnologias atreladas a Indústria 4.0 respondem a todo um sistema tecnológico. Por sistema tecnológico entende-se como um conjunto de tecnologias que se interligam, como por exemplo as tecnologias associadas à informação, ao qual dependem de tecnologias bases de captação de dados que alimentam os dispositivos de processamento de dados a fim de utilizar essa informação. Esses sistemas são caracterizados pela adoção de tecnologias motrizes, sendo essas servindo de base para a Indústria 4.0. As tecnologias base são, o Big Data, sua síntese em aplicação criando os sistemas "cyber físicos", a Internet das Coisas (IoT em inglês), robótica e inteligência artificial (IA).

Sobre o Big Data, ele atua através do fluxo de dados processado que são coletados em diversas formas dependendo do objetivo da empresa que o utiliza, por exemplo: empresas do setor energético são capazes de terem mais controle sobre, permitindo a conexão dos dispositivos e aplicativos utilizados no processo produtivo, gerando ganhos oriundos do aumento de informações disponíveis e, consequentemente, redução de custos acarretadas pelos mesmos. As capacidades de processamento de dados se relacionam diretamente com as demais tecnologias base da Indústria 4.0 e atuam como um dos principais atores geradores de um "pool de informações ".

Os sistemas "cyber físicos", ou CPS são a fusão do mundo físico real com o mundo virtual através das tecnologias de informações e processamento de dados tal como o Big Data anteriormente mencionado. O seu diferencial está na fusão de dados captados com o mundo físico através da criação de um sistema próprio de aprendizagem e sincronização em tempo real com os dispositivos e agentes ao longo da produção. Alguns autores pesquisaram e desenvolveram caracterizações para os CPS. De acordo com, Xu et al.(2018), os CPS são sistemas computacionais colaborativos, na qual há intensa conexão com o mundo ao redor e seus processos, além do mais, esses sistemas proporcionam o processamento e acesso de dados. Dessa forma, os CPS contribuem para o sistema de produção totalmente inteligente.

Varghese e Tandur (2014), dizem que os sistemas de produção baseados no CPS reagem a demandas externas e são considerados capazes em larga escala de autonomia, otimizando e adaptando a si mesmos. Essa escala de autonomia é baseada em um sistema descentralizado de contínuo auto aprendizado e otimização. Ou seja, os CPS transformam a interação e extração de conhecimento.

A internet das coisas (IoT) é um elemento central para a Indústria 4.0 devido ao seu poder conectivo, sensorial de ampla aplicação e extensão para as atividades econômicas, não se restringindo apenas às manufatureiras. A literatura vem buscando sintetizar o que é a IoT e como ela pode impactar no sistema produtivo para a Indústria 4.0. Xu (2018), afirma que para a indústria 4.0 a IoT oferece e promove soluções para problemas relacionadas à produção, além de transformar todo processo produtivo e suas 
operações em diversos sistemas industriais ligados a empresas digitais além de complexos ecossistemas industriais.

Aplicação da IoT pela indústria gera a criação de um novo tipo de fábrica, segundo Shrouf et al. (2014), ela propicia a criação das "smart factories". Caraterizadas por trazer maior proximidade entre o cliente e a produção, podendo participar de forma mais próxima do processo de design e criação dos produtos. Além disso, as "smart factories" fazem parte do sistema complexo ao qual circunda a indústria 4.0, essa complexidade é a adoção simultânea de Big Data e a IoT.

Em resumo, "smart factories" coletam e analisam dados de seus "smart products "e "smart aplications". Tendo assim dados do comportamento e características de seus consumidores, clientes e padrões de uso. Além disso a IoT tem impacto social direto no emprego e nas competências desse, uma vez que a adoção de tecnologias como a robótica e IA levam à menor necessidade do trabalho manual e rotineiros. Por fim, a IoT transforma e remodela toda a estrutura produtiva, trazendo uma maior conexão através de dispositivos e aplicativos.

À medida que a tomada de decisões dos aplicativos de IA se aperfeiçoa, melhor os robôs geridos por esses aplicativos trabalham, equiparando-os às capacidades decisórias de seres humanos, sendo esses realocados para outras tarefas de caráter mais sensorial (Schwab, 2018). Uma constatação da aplicação da IA está no aumento na utilização de drones e robôs industriais como aqueles que montam peças de carros sem ajuda humana, utilizando sua própria IA para executar funções produtivas, além de interações complexas que demandam capacidades mais precisas do que as humanas.

Por outro lado, esse processo carrega consigo desafios e riscos econômicos. Para os países em desenvolvimento a automação pode minar a industrialização nesses países, erodindo as vantagens de custo do trabalho que até então possuem. Assim, elos produtivos de que cadeias globais de valor que teriam sido levados para o exterior por grandes corporações oriundas de países desenvolvidos, estariam a partir dessas tecnologias sujeitas a retornar às nações sedes das grandes empresas transacionais (Cohen et al., 2016).

\section{Políticas industriais dos principais players}

Essa seção tem como objetivo expor a problemática referente às principais experiências nacionais de fomento ao desenvolvimento do novo paradigma técnico e econômico associado à Indústria 4.0. Foram selecionadas as experiências alemã, estadunidense, sul coreana, japonesa e chinesa. A característica em comum dessas experiencias está na formalização de uma estratégia industrial nacional que tenha objetivos correlatos as tecnologias da Indústria 4.0. Entretanto as motivações de cada país não são exatamente as mesmas.

As experiências nacionais são motivadas por uma série de fatores de cunho histórico institucional, passando pela percepção da importância de setores de alta tecnologia para o crescimento econômico do país, como também relevância geopolítica através da participação em cadeias regionais ou globais de valor.

\subsection{Alemanha}

Conforme Daudt e Willcox (2016), o capitalismo alemão passou por diversas modificações relevantes especialmente durante os anos 1990, exatamente após a unificação das duas Alemanha. Até o início da década de 2000 o país era visto como 
"sickman of Europe" para então ser considerado um caso de sucesso. A forma como Alemanha era vista só mudaria graças à modificação na orientação produtiva germânica com enfoque para a alta competitividade no setor de exportação de bens de capitais.

A respeito do papel das exportações para a Alemanha, Bastasin (2013), realça a importância que a orientação para a exportação foi capaz de proporcionar para o sistema de produção, permitindo que o país enfrentasse as mudanças geopolíticas e pudesse entrar com maior força nos mercados do mundo durante o maior desenvolvimento da fase de globalização.

Para se firmar e garantir a competitividade externa a indústria alemã visou, e ainda visa, principalmente a exportação dentro da Europa, seu maior mercado. Nela, a Alemanha obtém vantagens comparativas em uma larga categoria de produtos, tais como bens de capital, bens de consumo duráveis e farmacêuticos, além de uma boa fatia dos mercados internacionais. Bastasin (2013) destaca a importância do mercado europeu para as empresas alemãs, sendo possível dessa forma manter uma cadeia de valor dentro da Europa, mesmo fora da zona do Euro como no leste da Europa. Vale lembrar também que segundo Dauderstaedt (2012), não há um ator estratégico que coordena sozinho essa direção da indústria alemã, mas sim um esforço comum de empresas, Estado nacional e sindicatos (constitui assim a forma de política industrial bottom up ou seja, um esforço conjunto das camadas do setor privado e que se alinham com objetivos comuns sendo o Estado um direcionador da política industrial e não um arquiteto da mesma por si só).

Manter alta competitividade mostra-se estratégico para explicar o sucesso industrial (Daudt e Willcox, 2016). Uma vez que o mercado europeu propicia o alicerce para a manutenção e evolução do sistema industrial alemão. Daudt e Willcox, (2016) destacam a mudança que as grandes empresas alemãs passaram, centrando-se mais em importar partes e peças e concentrando-se nas etapas finais de montagem na Alemanha, para então exportar os bens finais de forte conteúdo tecnológico. Esse artifício propiciou às empresas alemãs competitividade externa, impulsionando sobretudo as exportações.

De acordo com Daudt e Willcox (2016), a partir do início da década o sistema alemão passou por novos ciclos, em todos esses casos a visão geral é de que as ações gerais estavam dentro do âmbito do que é chamado hoje como High Tech Strategy, que tem em si as fundações do que são as iniciativas para Indústria 4.0 alemã. Essas ações foram a primeira iniciativa construída a partir de um consenso nacional com objetivo comum sobre o processo de inovação e a necessidade de adoção e criação de novas tecnologias considerando o objetivo geral da Alemanha em consolidar sua liderança regional e global.

Segundo o relatório IEDI (2018), o projeto Industrie 4.0 foi incluído no plano High Tech 2020 lançado em março de 2012 (o termo Indústria 4.0 é derivado desse nome dado para política industrial alemã). Esse plano identifica dez projetos chave para o futuro, sendo considerados essenciais para a concretização dos objetivos atuais da política de inovação alemão. Ainda de acordo com o relatório do IEDI (2018), ligado diretamente ao projeto nacional Industrie 4.0 o país pretende assumir até 2020 a posição de liderança na provisão de sistemas cyber-físicos. Esse objetivo também é ressaltado por Wang et al. (2015), realçando que segundo o Ministério Federal Alemão de Pesquisa e Educação, a Indústria 4.0 é a flexibilização existente para criação de valor que é reforçada pelo 
aumento da aplicação cyber física na produção*. De acordo Hirsch-Kreinsen, (2016), a dominância tradicional da engenharia mecânica e bens de capitais industriais enfraqueceram dando espaço para uma direção fortemente pautada em tecnologias de informação indicadas pela Indústria 4.0.

À vista disso, a estratégia High Tech visa enfrentar os desafios impostos pela globalização e foi criada em vista de explorar as oportunidades em segmentos específicos em tecnologias transversais (Andreoni, 2016). Essa iniciativa tem como coordenação diversos agentes empresariais como por exemplo Volkswagen, Bosh, Kuka (essa última base da Indústria 4.0 alemã e recentemente foi comprada pela MIDEA Group Company of China), dentre outras.

Gráfico 1: Composição dos 20 principais produtos da pauta de exportação alemã principais produtos em 2017 (em Bilhões de dólares).

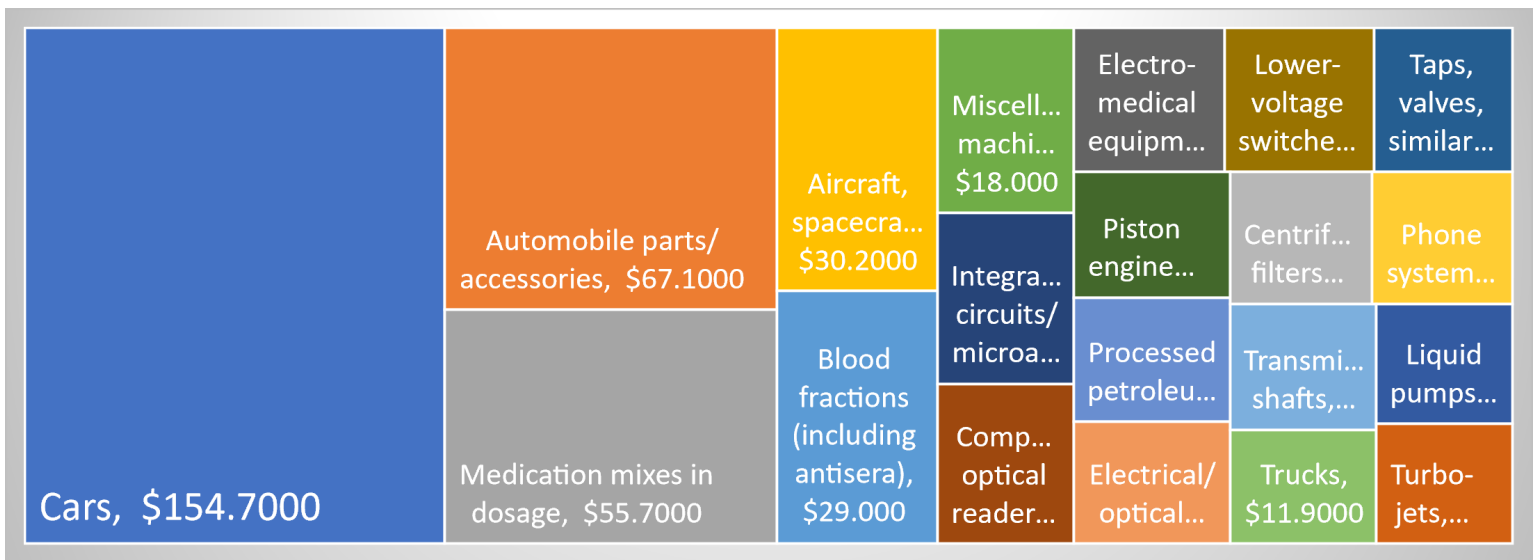

Fonte: World International Trade (http://www.worldstopexports.com).

Observa-se a dominância do setor automobilístico, químico e de bens de capital o que condiz com o histórico da industrialização alemã. Dessa forma, a Indústria 4.0 alemã visa salientar as vantagens competitivas alemãs para esses setores de maior competitividade.

\subsection{EUA}

A experiência norte americana em política industrial data dos primórdios da revolução americana, com Alexander Hamilton e sua defesa acerca de indústria nascente. Ao longo da história estadunidense fora desenvolvida uma ampla rede de infraestrutura institucional a fim de estimular o desenvolvimento de inovações tecnológicas estimulando o P\&D em diversas medidas, e incluindo políticas comerciais, além de exigências relativas ao conteúdo local (Daudt e Willcox, 2016).

Andreoni (2016), por sua vez afirma que o sucesso de hoje se deve a uma sequência de apoios ao longo de diversos ciclos de transformação da economia estadunidense. Entretanto, mesmo assim houve considerável perda de tecido industrial nas últimas décadas, e esse evento é constatado pela perda de atividades de P\&D ligadas à manufatura (Daudt e Willcox, 2016). O resultado é que os EUA enfrentam uma perda de conhecimento, impactando a formação de postos de trabalho tanto de maior valor

\$ "The German Federal Ministry of Education and Research defines Industry 4.0 as "the flexibility that exists in value-creating networks is increased by the application of cyber-physical production systems (CPPS)" Wang et al., (2015). 
agregado como de menor valor agregado, uma vez que a distância do chão de fábrica com a matriz também favorece que as atividades mais relevantes sejam progressivamente transferidas para fora.

Baily e Bosworth (2014) demonstram que a manufatura estadunidense caiu de aproximadamente $25 \%$ do seu PIB em 1960 para aproximadamente $12 \%$ em 2010. Por sua vez, em relação ao emprego houve queda de $25 \%$ para $10 \%$ entre 1960 e 2010 respectivamente. Para explicar a redução do número de empregos, se ancoraram na hipótese da produtividade, isto é, foi observado que o aumento da produtividade dentro do setor manufatureiro estadunidense não acompanhou proporcionalmente um aumento da demanda, isto é, o aumento da produtividade cresceu em um cenário com baixa elasticidade preço da demanda, o que levou ao fechamento de vagas no setor manufatureiro. Em resposta a esse quadro, foram elaboradas e realizadas políticas direcionadas ao setor manufatureiro. A literatura buscou destacar as essas políticas industriais voltadas para a Indústria 4.0

Segundo Liu, F. et al. (2018), desde junho de 2011 uma série de esforços nacionais chamados de "Advanced Manufacturing Partnership (AMP)" foram inaugurados pelo Conselho de Auxílio à Ciência e Tecnologia. Essa iniciativa traz o esforço conjunto do governo federal, indústria e universidades na criação de um ambiente propício às inovações, além de fomentar através de fundos governamentais novas tecnologias e design metodológicos. Também, durante o governo Obama foi aprovado no Congresso o programa "Revitalize American Manufacturing Act". O governo assim busca criar uma rede de inovação industrial chamada de Manufacturing USA. Essa rede é fomentada por institutos privados de financiamento misto (público e privado).

Segundo IEDI (2018), o "Revitalize American Manufacturing Act" é formado por 15 institutos regionais e através de recursos públicos e privados e de parceiros direcionam investimentos com a finalidade de acelerar o desenvolvimento e adoção de tecnologias industriais avançadas. Essa rede de inovações é formada por instituições denominadas Institute for the Management of Information Systems (IMIs), e é inspirada na experiência e o modelo alemão dos Institutos Fraunhoufer. Dentre elas está a destinação de US\$ 1 bilhão de para que fosse criado a National Network for Manufacturing Innovation (NNMI) voltado para a manufatura aditiva.

A formação desses institutos tem como finalidade comum a redução de custos e o enfrentamento dos riscos tecnológicos referentes à inovação no setor high tech. Contudo, cada instituo é conhecido por ter foco específico conforme destacado por Daudt e Willcox (2016). Alguns focam em áreas de pesquisa e desenvolvimento como tecnologia de semicondutores, materiais compósitos e manufatura aditiva. Eles atuam em parceria público privada com atores como o governo, universidades e o setor privado industrial.

A estratégia estadunidense para a Indústria 4.0 se pauta em uma reestruturação da sua indústria nacional fim de recuperar parte da manufatura perdida deslocada sobretudo para países asiáticos, a motivação disso se dá principalmente pela relação que a manufatura tem com a criação de postos de trabalho.

Apesar da sangria ao qual a indústria americana passa, o setor automobilístico, petrolífero (com relatividade de capital/trabalho elevada) e de bens de capitais ainda figuram com relevância na pauta de exportação estadunidense. $O$ gráfico a seguir demonstra essa composição da balança de exportação dos EUA em 2017: 
Gráfico 2: Composição da pauta de exportação estadunidenses, principais produtos em 2017 (em Bilhões de dólares).

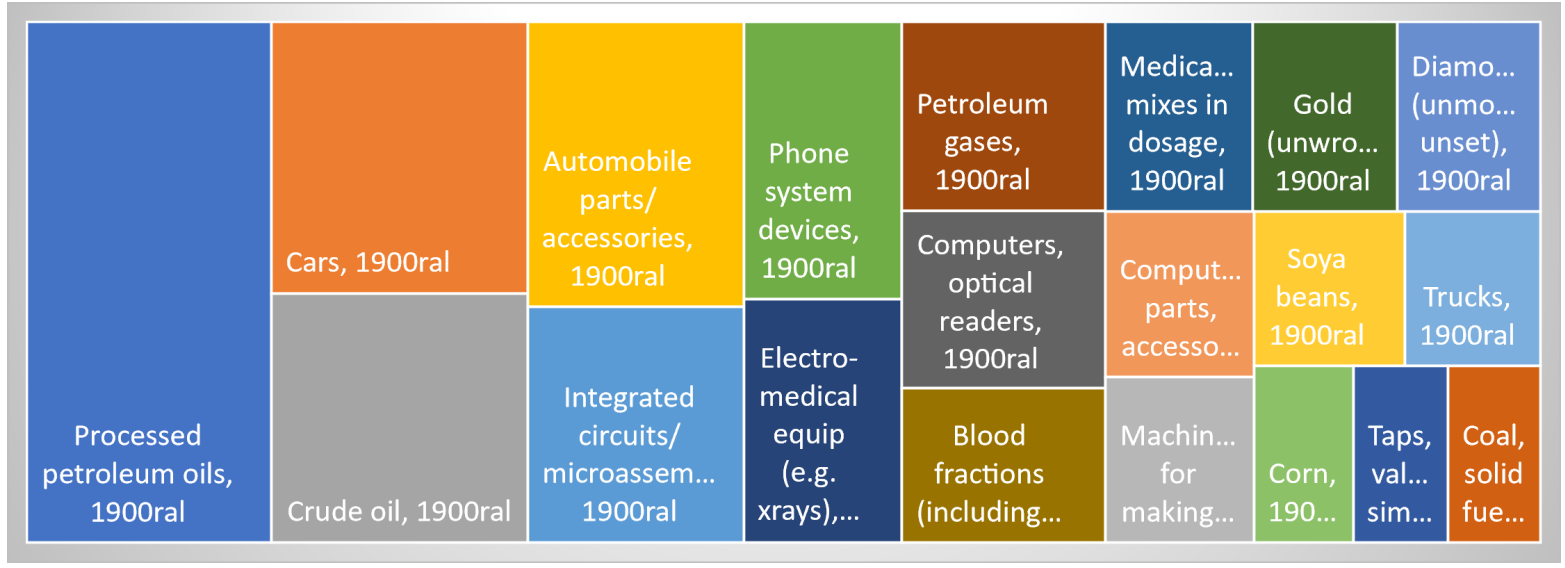

Fonte: World International Trade (http://www.worldstopexports.com).

O gráfico acima demonstra dominância de produtos sobretudo da indústria automobilística norte americana, entretanto a menor participação da indústria de alta tecnologia é visível através da pauta exportadora.

\subsection{Coréia do Sul}

As experiências do extremo oriente são em certo grau distintas das listadas anteriormente. Coréia do Sul têm características em comum no âmbito demográfico e também na forma pelas quais suas políticas industriais foram arquitetadas. Segundo Liu et al. (2011), durante o processo de catching up os governos sul coreano e japonês atuaram fortemente utilizando a política industrial e os programas de ciência e tecnologia (C\&T) além de institutos como peças chave. A Coréia do Sul tem uma história e experiência industrial ímpar. Ao longo das décadas de 1960 e 1980 a política industrial coreana seguiu uma trajetória semelhante à japonesa, entretanto de forma mais dramática do que a última (Chang et al., 2013).

Em seu início a industrialização coreana esteve sob influência de planejamento por parte do governo, através de seu Ministério do Planejamento que controlava o crédito e utilização de divisas (durante esse período, era escasso). Quando comparada a outros países tais como Japão e França, a Coréia do Sul se mostrou com maior intervenção das agências governamentais na política econômica e industrial de acordo com o relatório IEDI (2018).

As experiências industrializantes em direção a Indústria 4.0 coreana está relacionada à modernização e manutenção da posição que esse país atualmente ocupa no cenário manufatureiro global. IEDI (2018), se refere a elas como estratégias para preservação da liderança, juntamente com a Alemanha, visto que esses são atualmente países líderes em segmentos da manufatura de alto valor agregado internacional.

Esse fato pode ser constatado pelo lado coreano através do seu Plano Estratégico de Economia Criativa, mais especificamente pela iniciativa Movimento Inovação Industria 3.0 (IIM 3.0), criado pelo ministério coreano de comércio, indústria e energia, que carrega consigo semelhanças com o programa de Indústria 4.0 alemão. Liao et al. (2018) explicam que o plano foca na "smartization" de dez mil fábricas através da integração com a TI, software, serviços e produtos até o ano de 2020. 
Em sua abordagem a Coréia pretende preservar sua posição como um dos polos industriais mais relevantes do mundo e, para isso pretende inserir e aumentar o ritmo de inovação industrial. IEDI (2018) destacam o Plano de Médio e Longo prazo lançado pelo governo sul-coreano em dezembro de 2016, que visa preparar o país para o processo da Quarta Revolução Industrial: o objetivo é desenvolver tecnologias de informação inteligentes, tais como a Internet das Coisas, Big Data e tecnologias móveis. Esse plano prevê que as tecnologias da Indústria 4.0 desempenharão um papel fundamental para ganhos de produtividade e eficiência na indústria de transformação além dos demais setores da economia. A atuação do Estado Sul Coreano diretamente através do planejamento demonstra uma estratégia do estilo top down para a política industrial sul coreana.

Esses dados atentam para perda da relevância desses países no cenário manufatureiro mundial, o que coincide com as retomadas de políticas industriais pelos mesmos. Para a Coréia do Sul a pauta de exportação se configura da seguinte forma:

Gráfico 3: Composição da pauta de exportação sul coreana por produtos em 2017 (20 principais produtos e seu fluxo em bilhões de dólares).

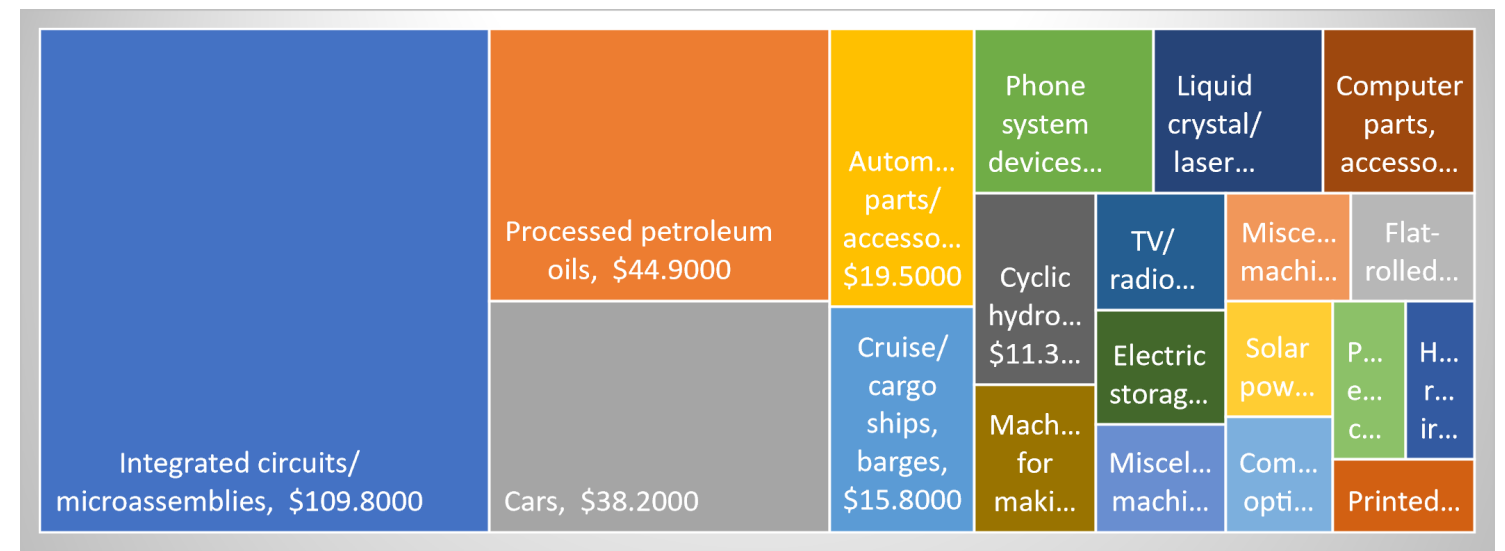

Fonte: World International Trade (http://www.worldstopexports.com).

Como observável pelo gráfico para a Coréia do Sul, o setor de eletrônica e bens de capital se faz de alta relevância, de forma a salientar seus objetivos acerca da Indústria 4.0. A dominância sobretudo do setor industrial de alta intensidade de capital voltado pra exportação faz com que a pressão por competitividade sul coreana se traduza na adoção de tecnologias high end tais como as da Indústria 4.0, dando foco para a otimização de suas fábricas com os CPS

\subsection{Japão}

O conceito da quarta revolução industrial no Japão começou a ser traçado em julho de 2010 segundo Liao et al. (2018), sendo o uso da energia solar, carros elétricos e redes elétricas os primeiros segmentos a serem mencionados. Contudo, apenas em 2015 as iniciativas para a Indústria 4.0 japonesa tomariam forma através do Quinto plano básico de tecnologia e ciência, publicado pelo Conselho de Ciência e Tecnologia e Inovação. As ações acolhem direcionada à Indústria 4.0 nipônica está na realização da liderança global na "Super Smart Society", e consistem no aprofundamento da IoT e o CPS para além das fábricas, integrando a sociedade como um todo.

Exemplo das políticas estratégicas nipônicas está no plano do governo anunciado em fevereiro de 2015 para a estratégia e desenvolvimento de robôs, chamada de Iniciativa Revolução Robótica (RRI), cujo objetivo é assegurar a posição do Japão no cenário da 
robótica. Para isso, essa estratégia conta com o desenvolvimento dos domínios em tecnológicas robóticas, além da criação de programações de alto valor agregado, além de contar com a difusão de softwares e hardwares de forma a servir de potencializador da política e ramificações dos diversos setores da indústria de transformação.

Segundo o relatório, a agenda política do governo japonês tem sido de objetivos de médio e longo prazo baseados na cooperação e parceria com o setor privado com estratégias focadas no desenvolvimento de domínios tecnológicos como, por exemplo, Robótica, TI e AI. Esses esforços tecnológicos buscam manter a competitividade japonesa nos setores de maior intensidade de capital, nos quais a economia japonesa se destaca por suas exportações. O gráfico a seguir demonstra a composição das exportações nipônicas:

Gráfico 4: Composição da pauta de exportação japonesa por produtos em 2017 (20 principais produtos e seu fluxo em bilhões de dólares).

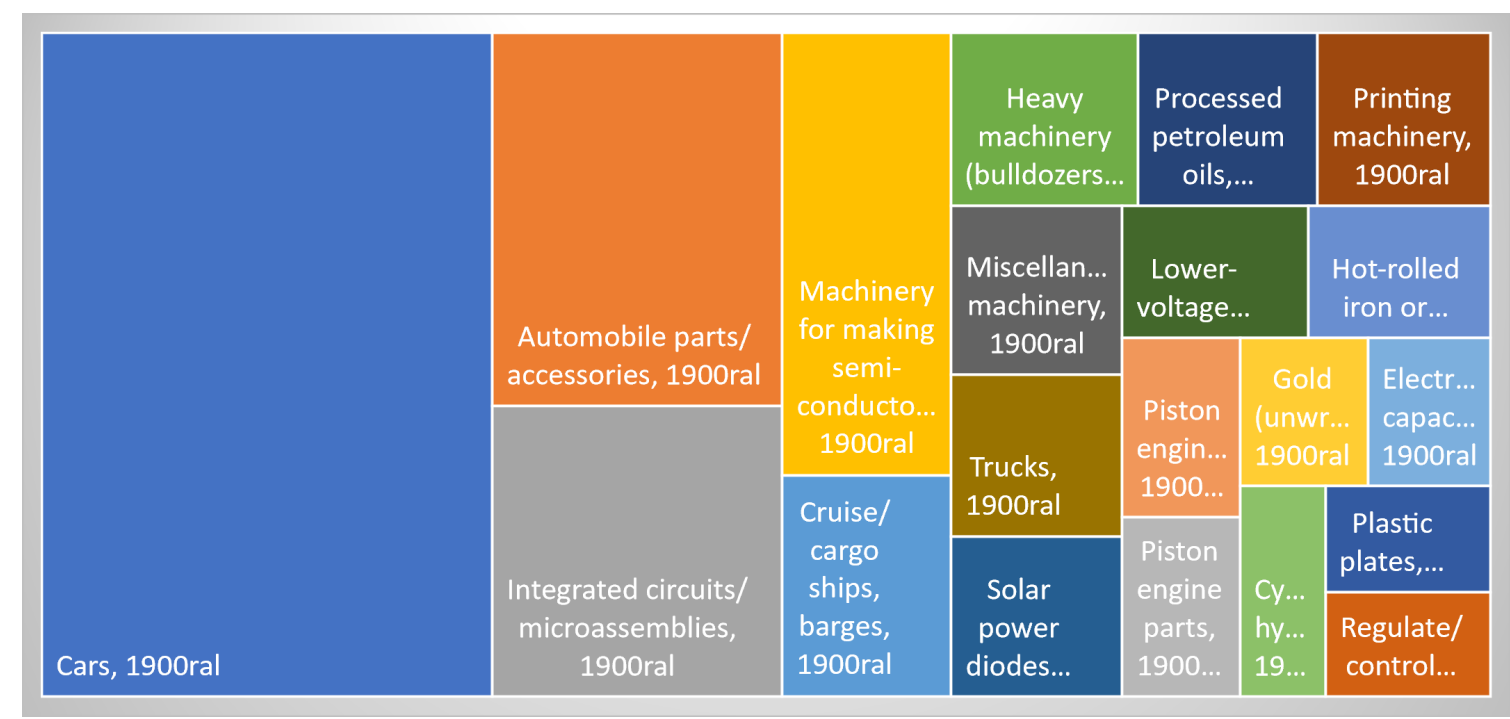

Fonte: World International Trade (http://www.worldstopexports.com).

Por meio do gráfico é possível concluir a importância da indústria automobilística e de bens de capital para a exportação japonesa. O comportamento da pauta de exportações dos países selecionados até então tem se comportado de forma semelhante, com produtos automotivos e bens de capital em destaque.

Em 2017 foi divulgado a estratégia nipônica para as tecnologias de IA utilizando a base do conceito de IA como serviço para que o mesmo seja incorporado às estratégias de médio e longo prazo para o desenvolvimento industrial e P\&D até o ano de 2030. Dessa forma o conjunto de implementação para a Indústria 4.0 japonesa configura-se como políticas do tipo top-down por conta do direcionamento do Estado por traz do incentivo a adoção e expansão de tecnologias chave para a Industria 4.0 no caso japonês.

\subsection{China}

Durante as últimas décadas a China emergiu no cenário global mostrando alto desempenho em diversas áreas, tais como desenvolvimento econômico, inserção externa e aprofundamento da presença em organismos internacionais. Por trás desse fenômeno estão algumas explicações sobre o funcionamento do seu planejamento econômico, sobretudo em um horizonte de longo prazo. 
A China em via contrária aos países desenvolvidos, como: Alemanha, EUA, Coréia do Sul, Japão, não figura entre os países de alta renda per capita. É um país em transição, que está fazendo seu catching up com políticas industriais nacionais, intensificadas pelo cenário competitivo e tecnológico da Indústria 4.0. Além disso, a China comporta um dos maiores e mais promissores mercados consumidores do mundo e possui uma atuação determinante em formações de políticas econômicas que reestruturam toda a estrutura de sua sociedade, principalmente através de planejamento econômico com visões de médio e longo prazo.

No decorrer da última década a China expandiu sua influência internacional em diversas áreas, com destaque para a manufatura e o comércio internacional, contudo o esgotamento do modelo voltado para exportações trouxe consigo a necessidade de modificações na conduta da política econômica interna. $\mathrm{O}$ gráfico a seguir demonstra a composição da pauta exportadora chinesa a fim de ter dimensão dos principais componentes responsáveis pela indústria chinesa:

Gráfico 5: Pauta de exportação chinesa por produtos em 2017 (20 principais produtos e seu fluxo em bilhões de dólares):

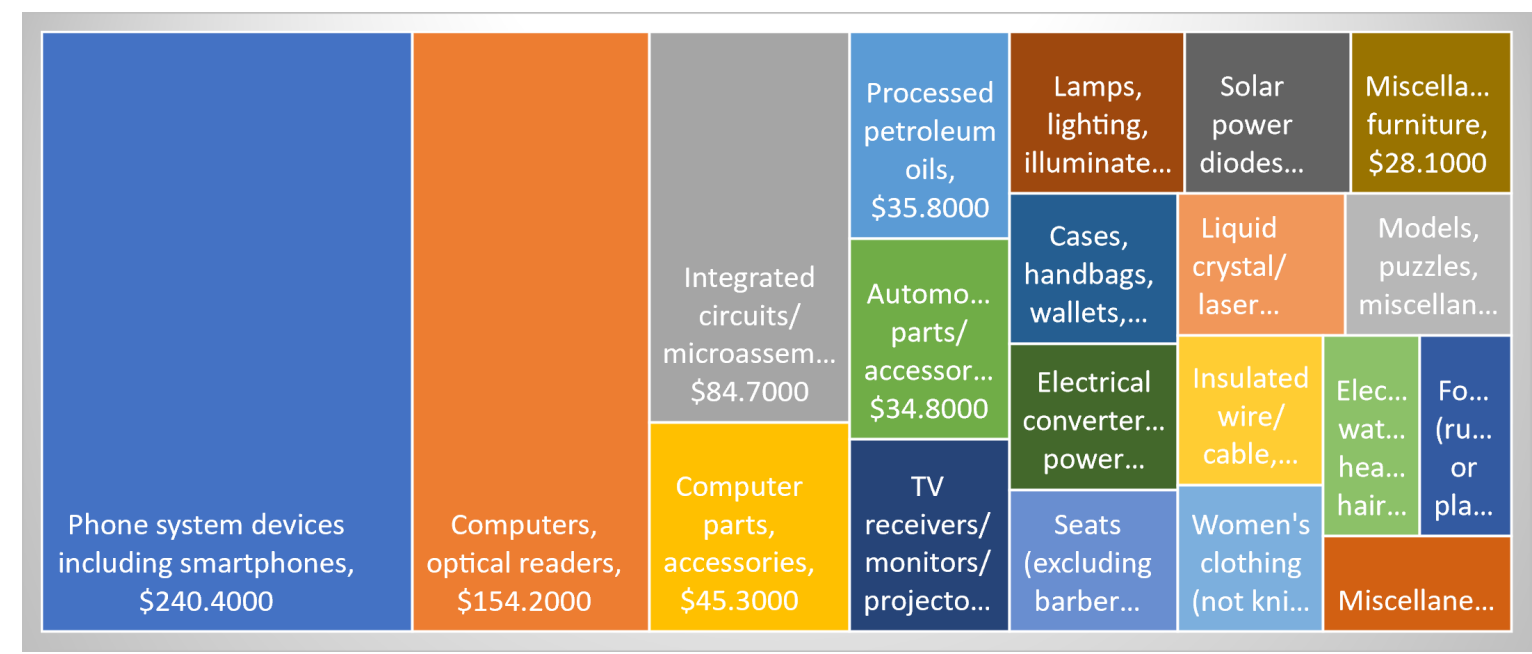

Fonte: World International Trade (http://www.worldstopexports.com).

Com base no Gráfico 5 é possível observar a importância da indústria de telefonia móvel, além da presença da indústria de computadores e acessórios. Esses dados corroboram com a problemática que os Estados Unidos da América, que tiveram parte de sua produção da indústria de computadores e tecnologia deslocadas para Ásia.

Além disso, os objetivos chineses para a Indústria 4.0 podem ser traçados de forma a aproveitar vantagens de industriais, nas quais ela se mostra dominante no mercado, como nos segmentos de smartphones e computadores observável no gráfico anterior. Esses produtos são baseados nas tecnologias de TI, base da Indústria 4.0.

Em resposta a recente onda de políticas voltadas à reindustrialização pelos países líderes em manufatura, e também em resposta a estratégia alemã Industrie 4.0, o Conselho de Estado chinês anunciou o plano "Made in China 2025". O plano Made in China 2025 é uma estratégia com direcionamento top-down (de cima para baixo), isto é, o líder governamental impõe as políticas e estratégias voltadas para evolução industrial na indústria manufatureira. Li (2017) afirma que o Made in China 2025 foca em melhorar a qualidade dos produtos chineses, criando uma capacidade sólida manufatureira, através do desenvolvimento de tecnologias avançadas chave, além da produção de partes essenciais de componentes para produtos maiores. 
Além disso, o plano lista as 10 áreas a serem desenvolvidas pelo estímulo as tecnologias da Indústria 4.0: veículos de energia limpa, próxima geração de tecnologia da informação, biotecnologia, novos materiais, aeroespacial, engenharia oceânica e embarcações high tech, equipamentos de trilhos avançados, robótica, equipamentos de energia, e maquinário para agricultura (Módolo e Hiratuka, 2017).

Os financiamentos do Made in China 2025 são oriundos de instituições públicas, bancos, fundos voltados para tecnologia, fundos para startups e fundos públicos (Li, Y., 2017). Em relação aos financiamentos para internet, Kupfer (2018) destaca que são estimulados de forma direta, através da expansão de crédito para pequenas firmas e plataformas de internet, encorajando crowfunding e o desenvolvimento de softwares open source, os quais podem ser desenvolvidos pela comunidade local, o que poderia gerar e expandir o ecossistema dessas empresas, criando uma nova forma de infraestrutura.

Além do Made in China, também há o One Belt One Road (OBOR), discutido primeiramente em 2013 e oficializado em 2015. o plano OBOR tornou-se um braço da geopolítica internacional chinesa, além de ter sinergia com a política industrial. O OBOR é um projeto ambicioso de longo prazo focado em infraestrutura, desenvolvimento e conectividade. Iniciativa do OBOR é de caráter transnacional envolvendo 64 países e 15 províncias chinesas, abarcando a região da Ásia e Europa. OBOR busca ampliação da dimensão da política industrial, que no caso chinês se alicerça na aquisição de empresas estrangeiras a fim de obter ganhos tecnológicos, marca, e standarts, entrando dessa forma em conjunção e apoio às demais iniciativas de políticas industriais (como o Made in China e o One Belt One Road).

O incentivo a expansão das empresas chinesas para o restante do mundo é observável por Antonio et al. (2017) destacam o papel do investimento estrangeiro direto chinês para o mundo, segundo eles o Conselho de Estado chinês apoia concretamente a compra de empresas estrangeiras como uma estratégia de expansão e absorção de tecnologias. Um exemplo está na compra de mais de $80 \%$ das ações da Kuka pela Midea Group, a Kuka é uma empresa base para a Indústria 4.0 alemã, e produz robôs industriais. Ainda segundo (Antonio et al. 2017) a China possui o maior mercado consumidor de robôs do mundo (em 2016 houve a aquisição de 68.556 unidades pela China totalizando $27 \%$ das vendas mundiais) segundo dados da IRF (2016).

A movimentação do epicentro manufatureiro é observável através de indicadores como o de registros de patentes. Uma vez que o centro manufatureiro se deslocou em parte para a China, isso significa que o escritório de patentes chinês aumentou o número total de patentes registradas conforme ilustra o gráfico a seguir:

Gráfico 5: Fluxo totais de aplicações de patentes nos escritórios nacionais respectivos países. 


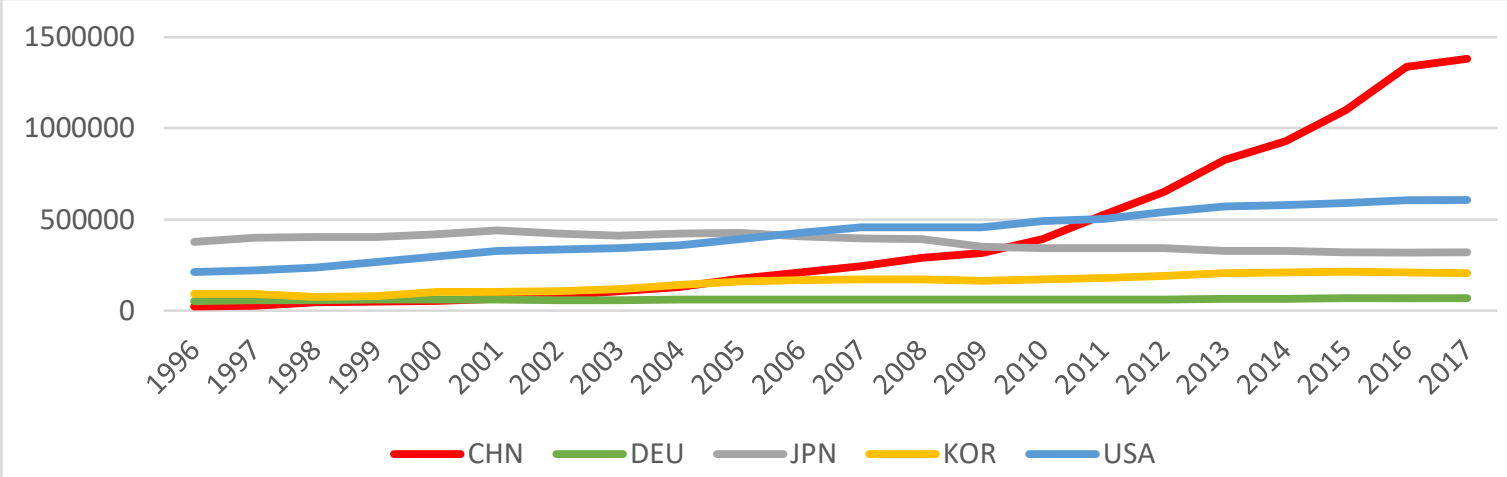

Fonte: Elaboração própria com base em dados do World Intelectual Property Organization (disponível em: https://www.wipo.int/).

O gráfico 5 demonstra a aplicação de patentes nos respectivos países em seus próprios escritórios. Nesse gráfico é possível observar a forte elevação das aplicações de patentes relacionadas à China, que saltou da terceira posição entre os países selecionados, para a primeira posição a partir de 2011. A partir de 2015 (data que inicia o Made in China 2025), é notável o aumento do ritmo de registro de patentes relacionadas às tecnologias da Indústria 4.0 para a China, em contrapartida, os demais países líderes no setor mantiveram ritmos menores. O que corrobora com a hipótese de que as políticas industriais recentes chinesas direcionadas para o ramo high tech estão surtindo efeito ao menos no registro de patentes em solo nacional.

Esses fatos trazem à luz uma característica comum quando se trata de China: o ator Estado por trás das reformas e modificações estruturais. Segundo Perez (2010), o governo chinês tem agido de forma a reorientar as decisões de produção focando sobretudo a Indústria 4.0 sintetizando uma estratégia do estilo top-down.

\section{Considerações Finais}

A seguir apresenta-se, num esforço de síntese dessa investigação, uma análise comparativa referente às estratégias industriais estudadas anteriormente destacando suas características essenciais e como se diferem uma das outras. Dessa forma a Quadro 1 traz esses conceitos para que possam ser comparados:

Quadro 1:Experiências Internacionais da Indústria 4.0

\begin{tabular}{|c|c|c|c|c|c|}
\hline Países & $\begin{array}{ll}\text { Formato } & \mathrm{da} \\
\text { política } & \\
\text { industrial } & \end{array}$ & $\begin{array}{l}\text { Política } \\
\text { Industrial }\end{array}$ & $\begin{array}{l}\text { Forma de } \\
\text { financiamento }\end{array}$ & $\begin{array}{l}\text { Tecnologias } \\
\text { incentivadas }\end{array}$ & Motivação \\
\hline China & Top down & $\begin{array}{l}\text { Made in } \\
\text { China } \\
\text { Internet Plus } \\
\text { One Belt } \\
\text { One Road } \\
\text { China Going } \\
\text { Global }\end{array}$ & $\begin{array}{l}\text { Financiamento } \\
\text { público com } \\
\text { fundos de } \\
\text { investimento } \\
\text { para } \\
\text { tecnologia, e } \\
\text { subsídios de } \\
\text { bancos } \\
\text { públicos }\end{array}$ & $\begin{array}{l}\text { Big Data, } \\
\text { Semicondutores, } \\
\text { IoT } \\
\text { Entretanto vale } \\
\text { destacar que a } \\
\text { China incentiva } \\
\text { todas as } \\
\text { tecnologias } \\
\text { ligadas a I4.0 }\end{array}$ & $\begin{array}{l}\text { Catching } \\
\text { Up, defesa } \\
\text { nacional, } \\
\text { soberania } \\
\text { geopolítica }\end{array}$ \\
\hline EUA & $\begin{array}{l}\text { Top down } \\
\text { com } \\
\text { abrangência de } \\
\text { institutos } \\
\text { inspirados na } \\
\text { política }\end{array}$ & $\begin{array}{l}\text { America } \\
\text { manufacture }\end{array}$ & $\begin{array}{l}\text { Fundos do } \\
\text { Departamento } \\
\text { de defesa dos } \\
\text { EUA } \\
\text { Parceria } \\
\text { Privada por } \\
\text { institutos }\end{array}$ & $\begin{array}{l}\text { Não existe uma } \\
\text { tecnologia } \\
\text { focada, mas sim } \\
\text { todas da I4.0. } \\
\text { Cuja finalidade } \\
\text { é revigorar o }\end{array}$ & $\begin{array}{l}\text { Recuperação } \\
\text { da posição } \\
\text { da sua } \\
\text { Industria. } \\
\text { Defesa } \\
\text { nacional e }\end{array}$ \\
\hline
\end{tabular}




\begin{tabular}{|c|c|c|c|c|c|}
\hline & $\begin{array}{l}\text { industrial } \\
\text { alemã }\end{array}$ & & $\begin{array}{ll}\text { Subsídios } & \text { a } \\
\text { Ciência } & \text { e } \\
\text { Tecnologia } & \\
\end{array}$ & $\begin{array}{l}\text { sistema } \\
\text { industrial }\end{array}$ & $\begin{array}{l}\text { soberania } \\
\text { geopolítica }\end{array}$ \\
\hline Alemanha & $\begin{array}{l}\text { Bottom up } \\
\text { com } \\
\text { participação de } \\
\text { institutos } \\
\text { empresas } \\
\text { privadas }\end{array}$ & Industrie 4.0 & $\begin{array}{l}\text { Aporte de } \\
\text { institutos } \\
\text { privados } \\
\text { relacionados a } \\
\text { indústria como } \\
\text { o Instituto } \\
\text { Fraunhofer }\end{array}$ & CPS & $\begin{array}{l}\text { Manutenção } \\
\text { da posição } \\
\text { entre os } \\
\text { líderes da } \\
\text { manufatura } \\
\text { global }\end{array}$ \\
\hline Japão & $\begin{array}{l}\text { com } \\
\text { participação de } \\
\text { institutos } \\
\text { empresas } \\
\text { privadas }\end{array}$ & $\begin{array}{l}\text { Robotic } \\
\text { Revolution } \\
\text { Incentive } \\
\text { (RRI) }\end{array}$ & $\begin{array}{l}\text { Financiamento } \\
\text { governamental } \\
\text { através de } \\
\text { subsídios para } \\
\text { pesquisa de } \\
\text { tecnologias } \\
\text { estratégicas }\end{array}$ & Robótica e IA & $\begin{array}{l}\text { Manutenção } \\
\text { da posição } \\
\text { entre os } \\
\text { líderes da } \\
\text { manufatura } \\
\text { global }\end{array}$ \\
\hline $\begin{array}{l}\text { Coréia do } \\
\text { Sul }\end{array}$ & $\begin{array}{lr}\text { Top down } \\
\text { através de } \\
\text { direcionamento } \\
\text { governamental } \\
\text { para } \\
\text { tecnologias } \\
\text { especificas e } \\
\text { apoiado por } \\
\text { institutos }\end{array}$ & $\begin{array}{l}\text { Manufacture } \\
\text { Movimetion } \\
\text { Inovattion } \\
3.0\end{array}$ & $\begin{array}{l}\text { Financiamento } \\
\text { público } \\
\text { privado e } \\
\text { apoio de } \\
\text { institutos de } \\
\text { tecnologias } \\
\text { estratégicas }\end{array}$ & CPS e IoT & $\begin{array}{l}\text { Manutenção } \\
\text { da posição } \\
\text { entre os } \\
\text { líderes da } \\
\text { manufatura } \\
\text { global }\end{array}$ \\
\hline
\end{tabular}

Fonte: Elaboração própria.

A China, como discutido ao longo do último capítulo, desempenha um esforço oriundo de uma estratégia ampla de desenvolvimento econômico, que combina diversas políticas de aspectos econômicos sociais e geopolíticos. Para isso, conta com um histórico de reformas e reestruturações econômicas tornando-a hábil no planejamento de médio e longo prazo. Os objetivos chineses para a Indústria 4.0 são amplos e fazem parte de um projeto de potência global, com um horizonte de décadas para ser alcançado. Entretanto, apesar dos objetivos não serem de curto prazo, a mesma demonstra esforços elevados com grandes volumes de financiamento para tecnologias estratégicas, quando comparadas às demais inciativas.

Os Estados Unidos têm o objetivo de manutenção do seu status quo como potência dominante mundialmente, para isso sua inspiração para política industrial está em recuperar o setor manufatureiro que sofreu perdas ao longo das últimas décadas. Essa estratégia configura-se com proximidade do setor de defesa, uma vez que o Departamento de Defesa é o responsável pelas políticas industriais estadunidenses. Controlar as tecnologias e standarts da Indústria 4.0 se faz importante para os Estados Unidos, uma vez que a dominância dessas tecnologias começou a se transferir para países "não aliados militarmente", como a China. Em relação ao emprego, a Indústria 4.0 traz uma oportunidade para os Estados Unidos recuperarem parte da atividade de menor valor agregado perdida para países periféricos, através de políticas comerciais agressivas (como se é observado recentemente pela guerra comercial entre EUA e a China, no governo de Donald Trump).

Já a estratégia alemã foi pioneira para a Indústria 4.0, e configura-se no seu princípio pela modernização e manutenção do seu status entre os principais produtores de manufatura no mundo. O destaque para os CPS que tem como objetivo aprofundar a integração das fábricas alemãs, economizando processos e tornando-as ainda mais competitivas. A Alemanha conta com um sistema de institutos que atuam a financiar 
projetos, gerar dados sobre o mercado, incentivar inovação tecnológica. Esse ecossistema inovativo faz com que a Alemanha tenha uma distinção na formulação da sua política industrial, sendo ela de caráter bottom up, isso é articulada pelos agentes econômicos e elevando-se até as esferas mais altas da sociedade. A indústria alemã enfrenta crescente ameaça chinesa devido a compra de empresas estratégicas para o setor industrial alemão por parte dos chineses.

A Coréia do Sul tem como objetivo a modernização de seu sistema fabril aumentando sua profundidade de interligações através do CPS. Além disso, o plano industrial coreano conta com um histórico de intervenções do Estado e planejamento de médio e longo prazo, característico de economias do extremo oriente. Para a Coréia do Sul manter-se na fronteira da manufatura global está correlacionado ao crescimento econômico do país, cuja exportações correspondem a boa parcela do PIB. Regionalmente, manter-se competitiva é necessário, uma vez que as empresas chinesas expandem sua esfera de atuação ao redor do globo. A Coréia do Sul tem nisso uma oportunidade para complementar e auferir espaços mais elevados no mercado de alta tecnologia asiática.

Por fim, o Japão tem motivações muito próximas da Coréia do Sul em preservar seu espaço entre as maiores potências manufatureiras globalmente. Para isso, o Japão aposta na robótica (em que é líder em produção) e IA. Além disso, o plano industrial japonês conta com características semelhantes ao da Coréia do Sul, apoiado diretamente pelo governo e com auxílio através de subsídios para implementação e modernização tecnológica.

\section{Referências}

ALLEN, B. G. C. Understanding China's AI Strategy: Clues to Chinese Strategic Thinking on Artificial Intelligence and National Security. n. February, 2019.

ANDREONI, A. Varieties of industrial policy: models, packages and transformation cycles. Columbia university press, 2016.

ARBIX, G. et al. O Brasil e a nova onda de manufatura avançada: o que aprender com a Alemanha, China e Estados Unidos. Novos Estudos - Cebrap, v. 36, n. 3, 2017.

BAILY, M. N.; BOSWORTH, B. P. US Manufacturing: Understanding Its Past and Its Potential Future. Journal of Economic Perspectives, v. 28, n. 1, p. 3-26, 2014.

BASTASIN, C. Germany: A Global Miracle and a European Challenge. Global Working Papers, n. May, p. 44, 2013.

CHANG, H.-J. ; A. A. M. K. International industrial policy experience and the lessons of the UK. [s.l: s.n.].

CHANG, H.-J.; ANDREONI, A.; KUAN, M. L. International industrial policy experiences and the lessons for the UK. Future of Manufacturing Project, v. 4, p. 76, 2013.

CHEN, S. et al. A vision of IoT: Applications, challenges, and opportunities with China Perspective. IEEE Internet of Things Journal, v. 1, n. 4, p. 349-359, 2014.

COHEN, M. et al. Off- , On- or Reshoring: Benchmarking of Current Manufacturing Location Decisions. Insights from the Global Supply Chain Benchmark Study 2015, n. March, p. 1-75, 2016.

DAUDT, G. M.; WILLCOX, L. D. Reflexões críticas a partir das experiências dos 
Estados Unidos e da Alemanha em manufatura avançada. BNDES Setorial, n. 44, p. 545, 2016.

HIRSCH-KREINSEN, H. "Industry 4.0" as Promising technology: Emergence, semantics and ambivalent character. Digitization of manufacturing and industrial work/ "Industry 4.0"., n. October, 2016.

IEDI. Estratégias Nacionais Para a industria 4.0. [s.l: s.n.]. Disponível em: $<\mathrm{http}$ //www.iedi.org.br/artigos/top/estudos_industria/20180705_estrategias_nacionais_ para_a_industria_4_0.html>.

JAMES MANYIKA et al. Manufacturing the future: The next era of global growth and innovation. McKinsey Global Institute, n. November, p. 184, 2012.

JASPERNEITE, J. Industrie 4.0: Alter Wein in neuen Schläuchen? [s.l: s.n.]. v. 12

LI, L. China's manufacturing locus in 2025: With a comparison of "Made-in-China 2025" and "Industry 4.0". Technological Forecasting and Social Change, n. May, p. 0-1, 2017.

LI, Y. Direction of Chinese Global Investments: Implications for Brazil. p. 357, 2017.

LIAO, Y. et al. The impact of the fourth industrial revolution: a cross-country/region comparison. Production, v. 28, n. 0, 2018.

LIU, F. et al. China's innovation policies: Evolution, institutional structure, and trajectory. Research Policy, v. 40, n. 7, p. 917-931, 1 set. 2011.

LIU, F. C. et al. China's innovation policies: Evolution, institutional structure, and trajectory. Research Policy, 2011.

MAJEROWICZ, E.; MEDEIROS, C. A. DE. Chinese Industrial Policy in the Geopolitics of the Information Age: the Case of Semiconductors. Revista de Economia Contemporânea, v. 22, n. 1, p. 1-28, 2018.

MÓDOLO, D. B.; HIRATUKA, C. The impact of Chinese competition on third markets: An analysis by region and technological category. Development Policy Review, v. 35, n. 6, p. 797-821, 2017.

ROBLEK, V.; MEŠKO, M.; KRAPEŽ, A. A Complex View of Industry 4.0. SAGE Open, v. 6, n. 2, 2016.

SCHWAB, K. N. D. Aplicando a Quarta Revolução Industrial. [s.l: s.n.].

SHROUF, F.; ORDIERES, J.; MIRAGLIOTTA, G. Smart factories in Industry 4.0: A review of the concept and of energy management approached in production based on the Internet of Things paradigm. IEEE International Conference on Industrial Engineering and Engineering Management, v. 2015-Janua, p. 697-701, 2014.

VARGHESE, A.; TANDUR, D. Wireless requirements and challenges in Industry 4.0Proceedings of 2014 International Conference on Contemporary Computing and Informatics, IC3I 2014. Anais...2014

WANG, S. et al. Towards smart factory for Industry 4.0: A self-organized multi-agent system with big data based feedback and coordination. Computer Networks, v. 101, p. $158-168,2015$. 
XU, L. DA; XU, E. L.; LI, L. Industry 4.0: state of the art and future trends. International Journal of Production Research, v. 7543, p. 1-22, 2018. 